\title{
Editorial: Peptidyl-Prolyl Isomerases in Human Pathologies
}

\author{
Tiziano Tuccinardi ${ }^{1}$ and Flavio Rizzolio ${ }^{2,3 *}$ \\ ${ }^{1}$ Department of Pharmacy, University of Pisa, Pisa, Italy, ${ }^{2}$ Department of Translational Research, Pathology Unit, National \\ Cancer Institute-CRO-IRCSS, Aviano, Italy, ${ }^{3}$ Department of Molecular Sciences and Nanosystems, Ca' Foscari University of \\ Venezia, Venice, Italy
}

Keywords: peptidyl-prolyl isomerases, therapy, signal transduction, human pathologies, cancer

Editorial on the Research Topic

Peptidyl-prolyl Isomerases in Human Pathologies

Peptidyl-prolyl isomerases (PPIases) are a group of evolutionarily conserved ubiquitous proteins expressed in both prokaryotic and eukaryotic cells. PPIases function as accelerating agents, speeding up the cis/trans conformational switch of specific substrates (Schiene-Fischer et al., 2011). Based on their affinity to immunosuppressive drugs such as cyclosporin A (CsA) and tacrolimus (FK506), they are classified into three different structurally and functionally classes: the CsA-binding cyclophilins, the FK506-binding proteins (FKBPs), and the parvulin-like PPIases, which do not bind immunosuppressants. PPIase-catalyzed isomerization can serve as a signal to other key proteins in different cellular processes such as the folding of newly synthesized proteins (Schmidpeter and Schmid, 2015), immune response (Nath and Isakov, 2015), neuronal differentiation (Ernst et al.,

OPEN ACCESS

Edited by:

Salvatore Salomone,

University of Catania,

Italy

${ }^{*}$ Correspondence:

Flavio Rizzolio

flavio.rizzolio@unive.it

Specialty section:

This article was submitted to Experimental Pharmacology and Drug Discovery,

a section of the journal

Frontiers in Pharmacology

Received: 14 June 2019

Accepted: 18 June 2019

Published: 11 July 2019

Citation:

Tuccinardi T and Rizzolio F (2019) Editorial: Peptidyl-Prolyl Isomerases in Human Pathologies.

Front. Pharmacol. 10:794. doi: 10.3389/fphar.2019.00794
2018), and cell cycle control (Yeh and Means, 2007; Rizzolio et al., 2012, Rizzolio et al., 2013; Cheng et al., 2017). Furthermore, several studies reported the involvement of PPIases in virion and parasite infection (Ünal and Steinert, 2014; Ernst et al., 2018; Ünal et al., 2018), vascular diseases (Perrucci et al., 2015), neurodegeneration (Blair et al., 2015), and many types of cancer (Girardini et al., 2011; Lee et al., 2011; La Montagna et al., 2012; Lucchetti et al., 2013). On this background, PPIases have been explored as potential diagnostics (Bao et al., 2004) and therapeutic targets (Rostam et al., 2015; Wei et al., 2015; Campaner et al., 2017; Russo Spena et al., 2018, Russo Spena et al., 2019).

This research topic conveyed together experts in the field of PPIases to generate a discussion regarding the mechanism of pathogenesis, the current status, and the innovative therapeutic strategies particularly in the oncology field.

In the review of Zannini et al. entitled "Oncogenic hijacking of the PIN1 signaling network," it was analyzed how cancer cells take over physiological signals through PIN1 at the molecular and cellular levels. The main molecular pathways such as RAS-MAPK, pRB, p53, NOTCH, c-MYC, WNT/ $\beta$-CATENIN, NF-kappaB, and PI3K/AKT were critically analyzed. The role of PIN1 in cell proliferation, metabolism, and stem cell reprogramming was discussed. Overall, this manuscript elegantly discussed the different and often opposite cell fates dictated by PIN1, placing its function in a context-dependent determination.

In "PIN1 in cell cycle control and cancer," Cheng and Tse reported how PIN1 fine tunes the cell cycle protein machinery, including the retinoblastoma protein, cyclin D1, cyclin E, p27, $\mathrm{Cdc} 25 \mathrm{C}$, and Wee1. All the principal steps of cell cycle progression in which PIN1 is involved were described, suggesting that PIN1 overexpression leads to cell cycle deregulation and malignant cell transformation. An analysis of the recently developed new PIN1 inhibitors was provided discussing their potential use for the treatment of different types of cancer. 
El Boustani et al. offered "A guide to PIN1 function and mutations across cancers." Through an analysis of COSMIC and cBioportal associated databases, they summarized all the mutations discovered among different types of cancer on PIN1. A molecular modeling analysis was provided to suggest the most probable activity of each single mutation and an updated summary of the most recently published inhibitors of PIN1 was also discussed.

In the research article entitled "Prolyl isomerase Pin1 directly regulates calcium/calmodulin-dependent protein kinase II activity in mouse brains" by Shimizu et al., it was speculated that PIN1 could regulate many brain diseases through calcium/ calmodulin-dependent protein kinase II (CaMKII) activity. PIN1 binds CaMKII in the mouse brain and suppresses its activity. CaMKII controls many proteins involved in neuronal functional disorders, including tau, synapsin I, a-amino-3-hydroxy-5methyl-4-isoxazolepropionic acid receptor, and N-methyl-Daspartate receptor. Although the mechanism of action has not been elucidated yet, these data suggest new PIN1 functions in preventing neurodegeneration.

The FKBP family was described in-depth by Kolos et al. in "FKBP ligands-where we are and where to go?" In this review, the principal and well-annotated FKBP proteins in the literature were analyzed, giving a critical overview of the related pathologies. The most prominent ligands were highlighted as possible chemical tools. An interesting "keep in mind" report was provided.

Ernst et al., in their research article entitled "Combined pharmacological inhibition of cyclophilins, FK506-binding

\section{REFERENCES}

Bao, L., Kimzey, A., Sauter, G., Sowadski, J. M., Lu, K. P., and Wang, D. G. (2004). Prevalent overexpression of prolyl isomerase Pin1 in human cancers. Am J Pathol 164, 1727-1737. doi: 10.1016/S0002-9440(10)63731-5

Blair, L. J., Baker, J. D., Sabbagh, J. J., and Dickey, C. A. (2015). The emerging role of peptidyl-prolyl isomerase chaperones in tau oligomerization, amyloid processing, and Alzheimer's disease. J. Neurochem. 133, 1-13. doi: 10.1111/ jnc. 13033

Campaner, E., Rustighi, A., Zannini, A., Cristiani, A., Piazza, S., Ciani, Y., et al. (2017). A covalent PIN1 inhibitor selectively targets cancer cells by a dual mechanism of action. Nat. Commun. 8, 15772. doi: 10.1038/ncomms15772

Cheng, C.-W., Leong, K.-W., Ng, Y.-M., Kwong, Y.-L., and Tse, E. (2017). The peptidyl-prolyl isomerase PIN1 relieves cyclin-dependent kinase 2 (CDK2) inhibition by the CDK inhibitor p27. J. Biol. Chem. 292, 21431-21441. doi: 10.1074/jbc.M117.801373

Ernst, K., Eberhardt, N., Mittler, A.-K., Sonnabend, M., Anastasia, A., Freisinger, S., et al. (2018). Pharmacological cyclophilin inhibitors prevent intoxication of mammalian cells with Bordetella pertussis toxin. Toxins (Basel). 10, 181. doi: 10.3390/toxins 10050181

Girardini, J. E., Napoli, M., Piazza, S., Rustighi, A., Marotta, C., Radaelli, E., et al. (2011). A Pin $1 /$ mutant p53 axis promotes aggressiveness in breast cancer. Cancer Cell 20, 79-91. doi: 10.1016/j.ccr.2011.06.004

La Montagna, R., Caligiuri, I., Maranta, P., Lucchetti, C., Esposito, L., Paggi, M. G., et al. (2012). Androgen receptor serine 81 mediates Pin1 interaction and activity. Cell Cycle 11, 3415-3420. doi: 10.1074/jbc.M111.325290

Lee, T. H., Pastorino, L., and Lu, K. P. (2011). Peptidyl-prolyl cis-trans isomerase Pin1 in ageing, cancer and Alzheimer disease. Expert Rev. Mol. Med. 13, e21. doi: 10.1017/S1462399411001906

Lucchetti, C., Caligiuri, I., Toffoli, G., Giordano, A., and Rizzolio, F. (2013). The prolyl isomerase Pin1 acts synergistically with CDK2 to regulate the basal activity of estrogen receptor $\alpha$ in breast cancer. PLoS One 8, e55355. doi: 10.1371/journal.pone.0055355 proteins, Hsp90, and Hsp70 protects cells from Clostridium botulinum C2 toxin," described how the chaperone Hsp90, cyclophilin Cyp40, and FKBP51 interact with the C2I enzymatic active component and regulate its translocation into the cytosol leading to the depolymerization of F-actin. The pharmacological inhibition of Hsp90, Hsp70, Cyps, and FKBPs enhanced the protection of cells against $\mathrm{C} 2$ cytotoxic effects.

Unal et al., in their research paper entitled "Pleiotropic Clostridioides difficile cyclophilin PpiB controls cysteinetolerance, toxin production, the central metabolism and multiple stress responses," reported an interactomic analysis of the sole cyclophilin-type PPIase of Clostridioides difficile (CdPpiB). In this paper, it was found that $\mathrm{CdPpiB}$ interacts with the major players of transcription, translation, protein folding, stress response, and the central metabolism regulating bacterial pathogenicity.

\section{AUTHOR CONTRIBUTIONS}

All authors listed have made substantial, direct, and intellectual contribution to the work and approved it for publication.

\section{ACKNOWLEDGMENTS}

FR is grateful to and would like to recognize the Associazione Italiana per la Ricerca sul Cancro-My First AIRC (n. 15639).
Nath, P. R., and Isakov, N. (2015). Insights into peptidyl-prolyl cis-trans isomerase structure and function in immunocytes. Immunol. Lett. 163, 120-131. doi: 10.1016/j.imlet.2014.11.002

Perrucci, G. L., Gowran, A., Zanobini, M., Capogrossi, M. C., Pompilio, G., and Nigro, P. (2015). Peptidyl-prolyl isomerases: a full cast of critical actors in cardiovascular diseases. Cardiovasc. Res. 106, 353-364. doi: 10.1093/cvr/ cvv096

Rizzolio, F., Caligiuri, I., Lucchetti, C., Fratamico, R., Tomei, V., Gallo, G., et al. (2013). Dissecting Pin1 and phospho-pRb regulation. J Cell Physiol 228, 73-77. doi: $10.1002 /$ jcp. 24107

Rizzolio, F., Lucchetti, C., Caligiuri, I., Marchesi, I., Caputo, M., Klein-Szanto, A. J., et al. (2012). Retinoblastoma tumor-suppressor protein phosphorylation and inactivation depend on direct interaction with Pin1. Cell Death Differ. 19, 1152-1161. doi: 10.1038/cdd.2011.202

Rostam, M. A., Piva, T. J., Rezaei, H. B., Kamato, D., Little, P. J., Zheng, W., et al. (2015). Peptidyl-prolyl isomerases: functionality and potential therapeutic targets in cardiovascular disease. Clin. Exp. Pharmacol. Physiol. 42, 117-124. doi: 10.1111/1440-1681.12335

Russo Spena, C., De Stefano, L., Palazzolo, S., Salis, B., Granchi, C., Minutolo, F., et al. (2018). Liposomal delivery of a Pin1 inhibitor complexed with cyclodextrins as new therapy for high-grade serous ovarian cancer. J. Control. Release 281, 1-10. doi: 10.1016/j.jconrel.2018.04.055

Russo Spena, C., De Stefano, L., Poli, G., Granchi, C., El Boustani, M., Ecca, F., et al. (2019). Virtual screening identifies a PIN1 inhibitor with possible antiovarian cancer effects. J. Cell. Physiol. 234, 15708-15716. doi: 10.1002/jcp.28224

Schiene-Fischer, C., Aumüller, T., and Fischer, G. (2011). Peptide bond cis/trans isomerases: a biocatalysis perspective of conformational dynamics in proteins. Top. Curr. Chem. 328, 35-67. doi: 10.1007/128_2011_151

Schmidpeter, P. A. M., and Schmid, F. X. (2015). Prolyl isomerization and its catalysis in protein folding and protein function. J. Mol. Biol. 427, 1609-1631. doi: 10.1016/j.jmb.2015.01.023

Ünal, C. M., Berges, M., Smit, N., Schiene-Fischer, C., Priebe, C., Strowig, T., et al. (2018). PrsA2 (CD630_35000) of Clostridioides difficile is an active 
parvulin-type PPIase and a virulence modulator. Front. Microbiol. 9, 2913. doi: 10.3389/fmicb.2018.02913

Ünal, C. M., and Steinert, M. (2014). Microbial peptidyl-prolyl cis/trans isomerases (PPIases): virulence factors and potential alternative drug targets. Microbiol. Mol. Biol. Rev. 78, 544-571. doi: 10.1128/MMBR.00015-14

Wei, S., Kozono, S., Kats, L., Nechama, M., Li, W., Guarnerio, J., et al. (2015). Active Pin1 is a key target of all-trans retinoic acid in acute promyelocytic leukemia and breast cancer. Nat. Med. 21, 457-466. doi: 10.1038/nm.3839

Yeh, E. S., and Means, A. R. (2007). PIN1, the cell cycle and cancer. Nat. Rev. Cancer 7, 381-388. doi: 10.1038/nrc2107
Conflict of Interest Statement: The authors declare that the research was conducted in the absence of any commercial or financial relationships that could be construed as a potential conflict of interest.

Copyright $\odot 2019$ Tuccinardi and Rizzolio. This is an open-access article distributed under the terms of the Creative Commons Attribution License (CC BY). The use, distribution or reproduction in other forums is permitted, provided the original author(s) and the copyright owner(s) are credited and that the original publication in this journal is cited, in accordance with accepted academic practice. No use, distribution or reproduction is permitted which does not comply with these terms. 